Supplement of

\title{
Experimental determination of Henry's law constants of difluoromethane (HFC-32) and the salting-out effects in aqueous salt solutions relevant to seawater
}

\section{Shuzo Kutsuna}

Correspondence to: Shuzo Kutsuna (s-kutsuna@ aist.go.jp)

The copyright of individual parts of the supplement might differ from the CC BY 3.0 License. 
10 S1. Equilibrium time for the PRV-HS method experiments

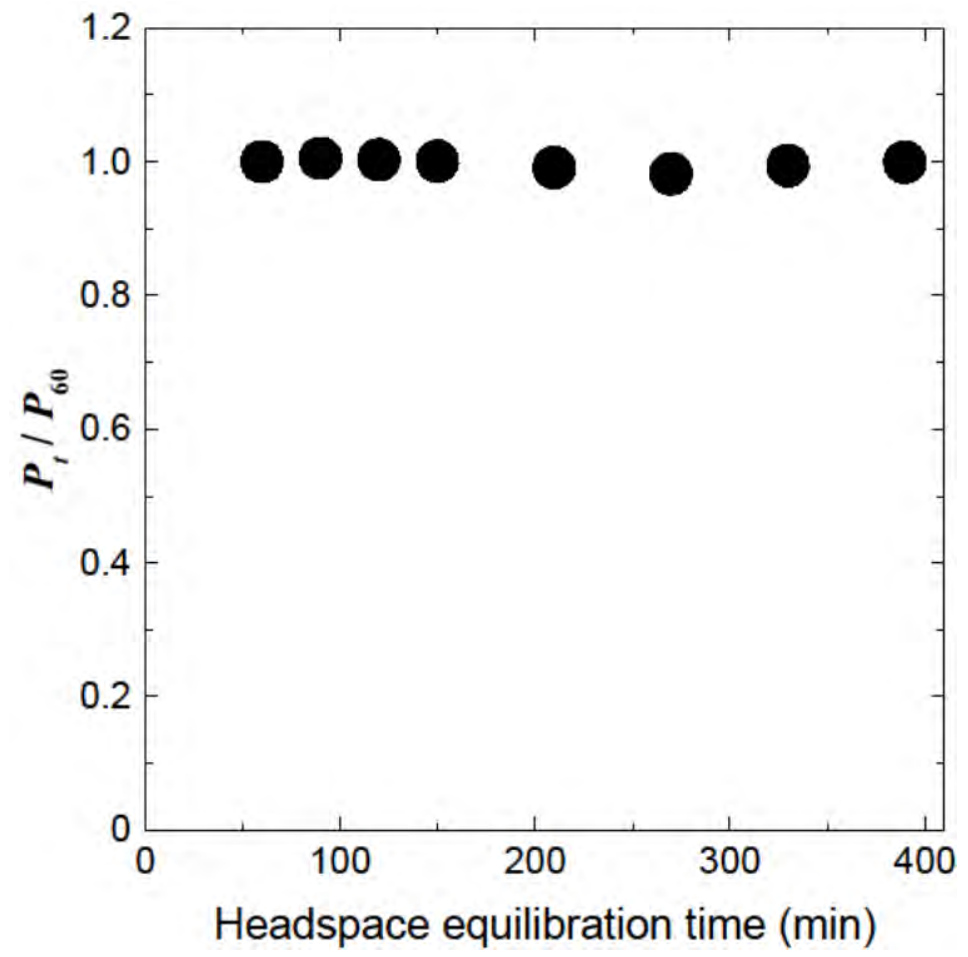

Figure S1. Relative areas of GC-MS peaks for $\mathrm{CH}_{2} \mathrm{~F}_{2}$ versus headspace time duration for equilibration of $9.0 \mathrm{~cm}^{3}$ of aqueous $\mathrm{CH}_{2} \mathrm{~F}_{2}$ at $353 \mathrm{~K}$. 


\section{S2. An example of the IGS method experiments}

Figure S2 shows an example of time profile of $P_{t}$ and how to calculate the $k_{1}$ value for the IGS method experiments. The $k_{1}$ value at each time was calculated by fitting nearest three data of $P_{t}$ for each time. The average of the $k_{1}$ values is given as the $k_{1}$ value for the experimental run. Two standard deviation of the $k_{1}$ values gives errors of the $k_{1}$ value for the

5 experimental run.

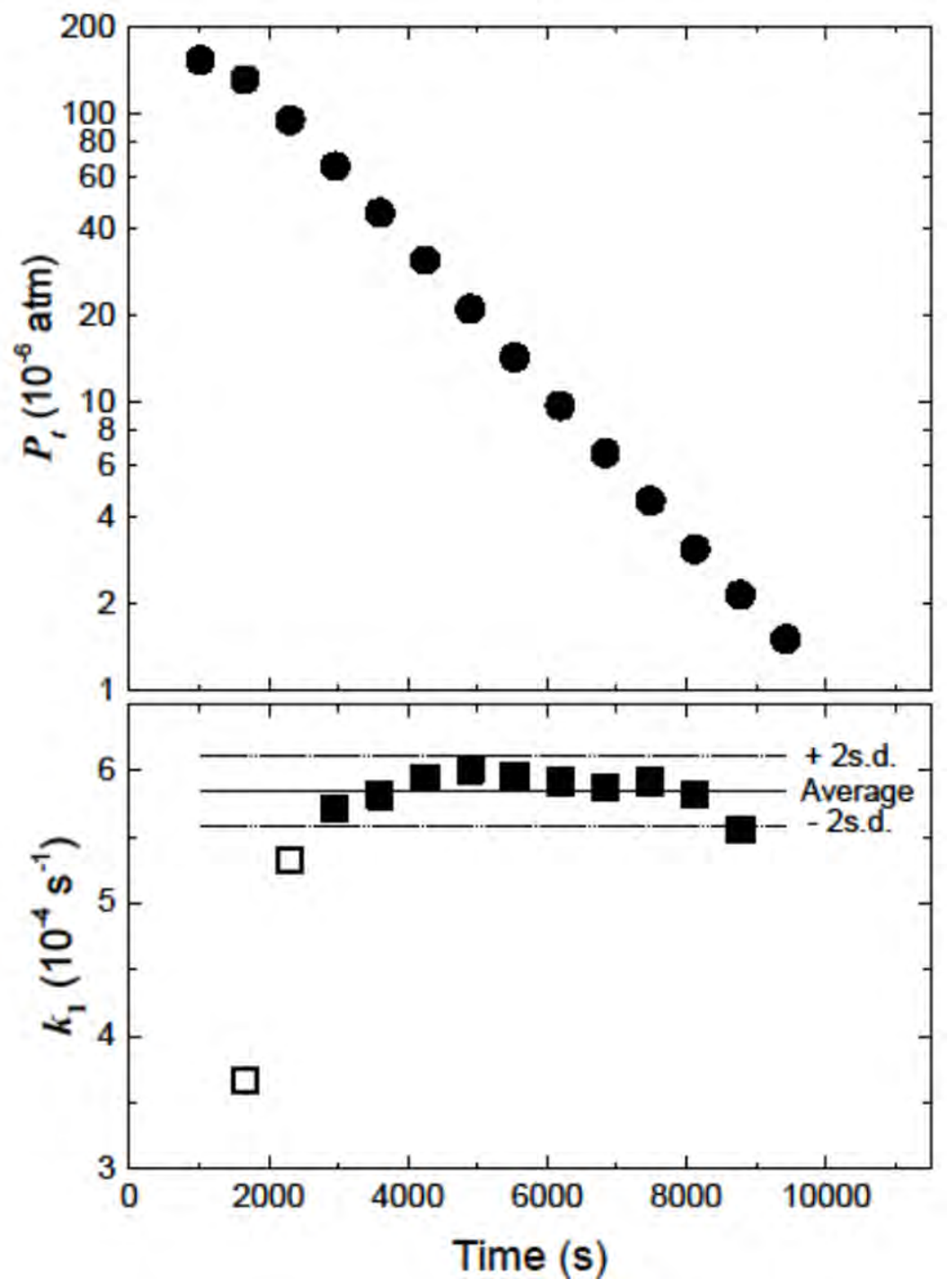

Figure S2. An IGS experimental result for $V=0.350 \mathrm{dm}^{3}$ and $F=3.32 \times 10^{-4} \mathrm{dm}^{3} \mathrm{~s}^{-1}$ at $25^{\circ} \mathrm{C}$. (upper panel) time profile of $P_{t}$; (lower panel) values of $k_{1}$ calculated by fitting nearest three data of $P_{t}$ for each time with respect to Eq. (1). 


\section{S3. Results of the PRV-HS method experiments}

Figure S3 illustrates the results of a PRV-HS experiment at $313 \mathrm{~K}$. In panel A, peak area $\left(S_{i j}\right)$ is plotted against the volume of the $\mathrm{CH}_{2} \mathrm{~F}_{2}$ gas mixture added $\left(v_{j}\right)$ for $V_{i}=9.0,7.5,6.0,4.5,3.0$, and $1.5 \mathrm{~cm}^{3}$. For each $V_{i}$, the data form a straight line intersecting the origin, indicating that $S_{i j}$ is proportional to $v_{j}$ for vials with the same value of $V_{i}$. The slope $\left(L_{i}\right)$ of each

5 line is obtained by linear regression with respect to Eq. (8), and the reciprocal of the slope $\left(L_{i}^{-1}\right)$ is plotted against the phase ratio $\left(V_{i} / V_{0}\right)$ in panel B of Fig. S3. Plots of $L_{i}^{-1}$ and $V_{i} / V_{0}$ obey Eq. (9). Table S1 lists the values of $L_{i}^{-1}$, the slopes and the intercepts for linear regression with respect to Eq. (9), and the $K_{\mathrm{H}}(T)$ values calculated from the slopes and the intercepts. Two measurements of $K_{\mathrm{H}}(T)$ were carried out at each temperature.

Furthermore, the $K_{\mathrm{H}}(T)$ values, along with errors of them at $95 \%$ confidence level, were also estimated by non-liner

10 fitting of the two datasets simultaneously at each temperature by use of Eq. (11) (Fig. S4). The $K_{\mathrm{H}}(T)$ values and their errors thus estimated are plotted in Fig. 2 and are listed in Table S1.

Table S1. $L_{i}$ values for various $V_{i} / V_{0}$ ratios at various temperatures, slopes and intercepts for linear regression with respect to Eq.

(10), $K_{\mathrm{H}}(T)$ values calculated from the slopes and intercepts, and $K_{\mathrm{H}}(T)$ values and the errors at $95 \%$ confidence level estimated

by non-linear fitting the two datasets simultaneously at each temperature (Fig. S4) with respect to Eq. (11).

\begin{tabular}{|c|c|c|c|c|c|c|c|c|c|c|c|}
\hline \multirow{2}{*}{$\begin{array}{c}T \\
(\mathrm{~K})\end{array}$} & \multicolumn{6}{|c|}{ 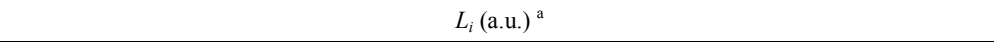 } & \multirow{2}{*}{$\begin{array}{l}\text { Eq. (10) } \\
\text { Intercept }\end{array}$} & \multirow{2}{*}{$\begin{array}{l}\text { Eq. (10) } \\
\text { Slope }\end{array}$} & \multicolumn{3}{|c|}{$K_{\mathrm{H}}\left(\mathrm{M} \mathrm{atm}^{-1}\right)$} \\
\hline & $V_{\mathrm{i}} / V=0.421$ & 0.351 & 0.280 & 0.210 & 0.140 & 0.070 & & & Eq. (10) & Eq. $(11)^{b, c}$ & Eq. $(13)^{b}$ \\
\hline \multirow{2}{*}{353} & $3.226 \pm 0.002$ & $3.270 \pm 0.026$ & $3.330 \pm 0.004$ & $3.391 \pm 0.008$ & $3.462 \pm 0.014$ & $3.526 \pm 0.009$ & 3.581 & -0.870 & 0.026 & \multirow{2}{*}{$\begin{array}{c}0.027 \\
\pm 0.002 \\
( \pm 0.003)\end{array}$} & \multirow{2}{*}{$\begin{array}{c}0.028 \\
\pm 0.003\end{array}$} \\
\hline & $2.044 \pm 0.006$ & $2.050 \pm 0.012$ & $2.112 \pm 0.010$ & $2.132 \pm 0.009$ & $2.186 \pm 0.021$ & $2.209 \pm 0.011$ & 2.248 & -0.513 & 0.027 & & \\
\hline \multirow{2}{*}{343} & $3.000 \pm 0.018$ & $3.025 \pm 0.009$ & $3.070 \pm 0.008$ & $3.089 \pm 0.015$ & $3.117 \pm 0.015$ & $3.148 \pm 0.018$ & 3.179 & -0.423 & 0.031 & \multirow{2}{*}{$\begin{array}{c}0.031 \\
\pm 0.001 \\
( \pm 0.002)\end{array}$} & \multirow{2}{*}{$\begin{array}{c}0.031 \\
\pm 0.002\end{array}$} \\
\hline & $1.949 \pm 0.004$ & $1.955 \pm 0.005$ & $1.968 \pm 0.003$ & $1.998 \pm 0.004$ & $2.020 \pm 0.002$ & $2.030 \pm 0.009$ & 2.050 & -0.258 & 0.031 & & \\
\hline \multirow{2}{*}{333} & $3.247 \pm 0.018$ & $3.234 \pm 0.018$ & $3.243 \pm 0.015$ & $3.241 \pm 0.010$ & $3.247 \pm 0.009$ & $3.223 \pm 0.013$ & 3.231 & 0.034 & 0.037 & \multirow{2}{*}{$\begin{array}{c}0.036 \\
\pm 0.003 \\
( \pm 0.004)\end{array}$} & \multirow{2}{*}{$\begin{array}{c}0.035 \\
\pm 0.002\end{array}$} \\
\hline & $3.080 \pm 0.009$ & $3.044 \pm 0.006$ & $3.082 \pm 0.005$ & $3.127 \pm 0.009$ & $3.113 \pm 0.008$ & $3.134 \pm 0.014$ & 3.149 & -0.213 & 0.034 & & \\
\hline \multirow{2}{*}{323} & $3.208 \pm 0.011$ & $3.190 \pm 0.008$ & $3.133 \pm 0.010$ & $3.134 \pm 0.011$ & $3.092 \pm 0.008$ & $3.093 \pm 0.006$ & 3.055 & 0.355 & 0.042 & \multirow{2}{*}{$\begin{array}{c}0.043 \\
\pm 0.002 \\
( \pm 0.004)\end{array}$} & \multirow{2}{*}{$\begin{array}{c}0.040 \\
\pm 0.001\end{array}$} \\
\hline & $3.357 \pm 0.010$ & $3.289 \pm 0.014$ & $3.275 \pm 0.005$ & $3.233 \pm 0.004$ & $3.226 \pm 0.016$ & $3.160 \pm 0.001$ & 3.135 & 0.496 & 0.044 & & \\
\hline \multirow{2}{*}{313} & $3.245 \pm 0.018$ & $3.185 \pm 0.013$ & $3.100 \pm 0.015$ & $3.022 \pm 0.012$ & $2.995 \pm 0.012$ & $2.915 \pm 0.011$ & 2.848 & 0.935 & 0.052 & \multirow{2}{*}{$\begin{array}{c}0.052 \\
\pm 0.003 \\
( \pm 0.005)\end{array}$} & \multirow{2}{*}{$\begin{array}{c}0.047 \\
\pm 0.001\end{array}$} \\
\hline & $2.162 \pm 0.031$ & $2.134 \pm 0.010$ & $2.060 \pm 0.014$ & $2.029 \pm 0.018$ & $1.992 \pm 0.010$ & $1.925 \pm 0.018$ & 1.896 & 0.612 & 0.052 & & \\
\hline
\end{tabular}

a. Errors are $2 \sigma$ for the regression only.; b. Errors are those at $95 \%$ confidence level for the regression only.; c. Number in parenthesis represents both errors at $95 \%$ confidence level for the regression and potential systematic bias $( \pm 4 \%)$. 


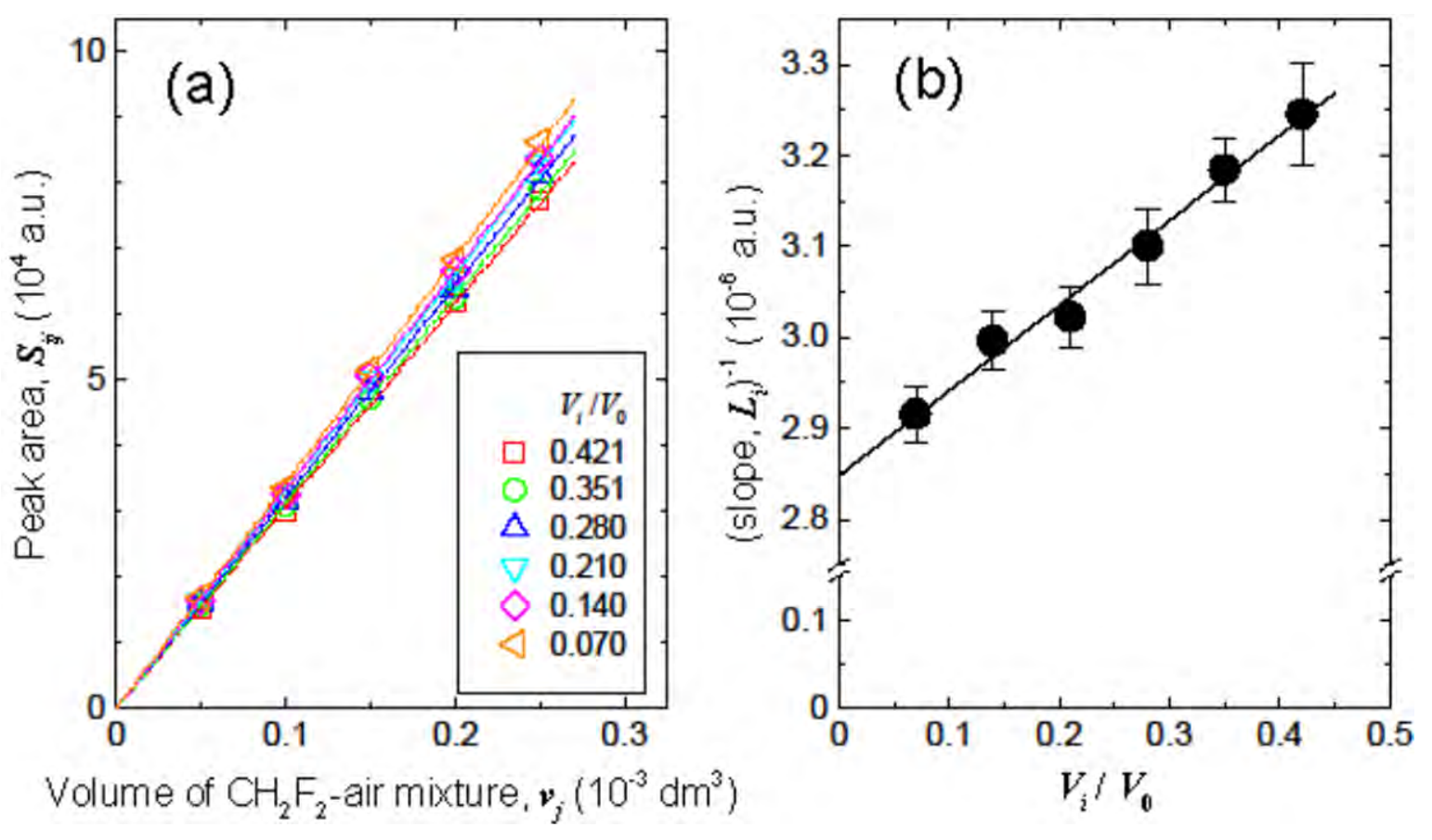

Figure S3. Headspace GC-MS measurements for six series of test samples containing water $\left(V_{i}\right.$ in $\left.\mathrm{cm}^{3}\right)$ to which a $\mathrm{CH}_{2} \mathrm{~F}_{2}-\mathrm{air}$ mixture was added $\left(v_{j}\right.$ in $\left.\mathrm{cm}^{3}\right)$ at $313 \mathrm{~K}$. (a) Plot of peak area $\left(S_{i j}\right)$ versus $v_{j}$ for test samples containing volume $V_{i}$ of water. Slope $\left(L_{i}\right)$ was obtained by linear fitting of the data to Eq. (8) for samples of the same $V_{i}$ (b) Plot of $L_{i}^{-1}$ versus $V_{i} / V_{0}$ fitted to Eq. (10).
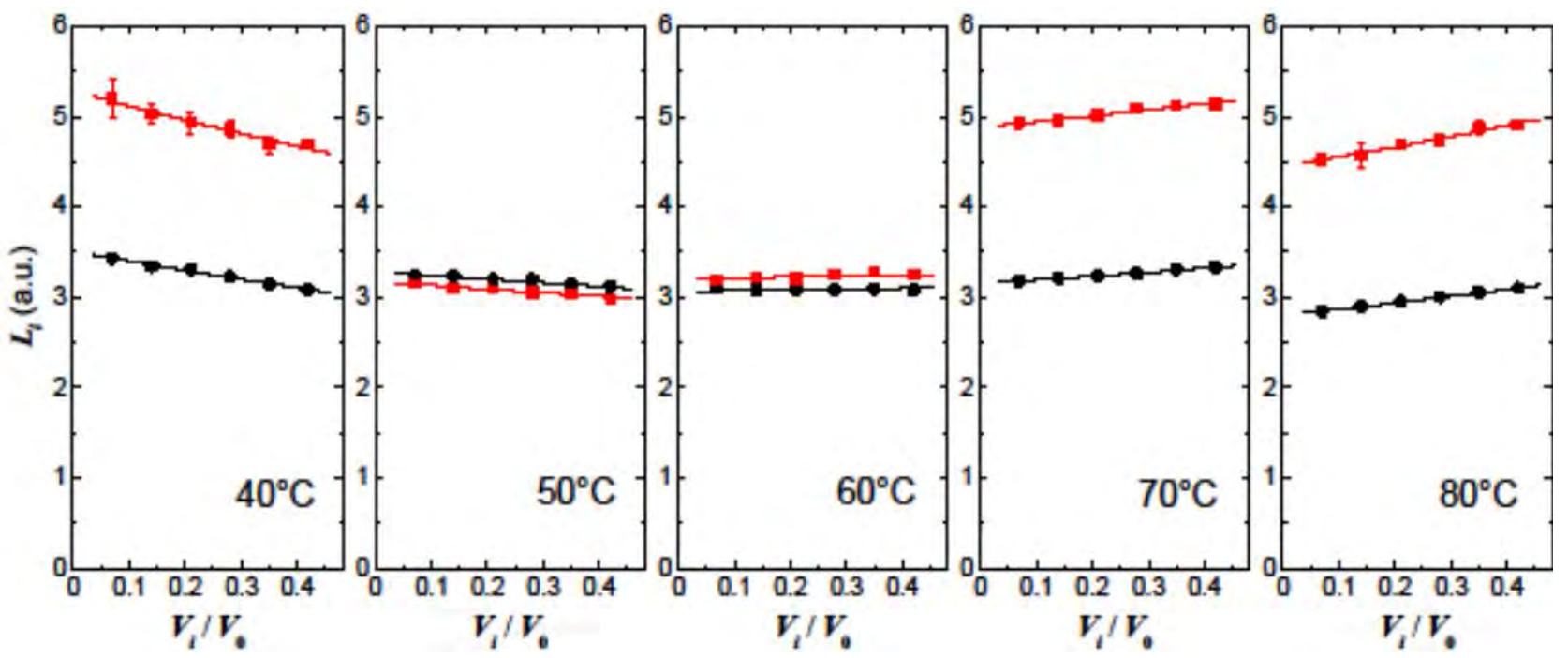

Figure S4. Plot of $L_{i}$ versus $V_{i} / V_{0}$ for the PRV-HS measurements at each temperature. Bold curves represent the simultaneous fitting of the two datasets at each temperature by Eq. (11). 


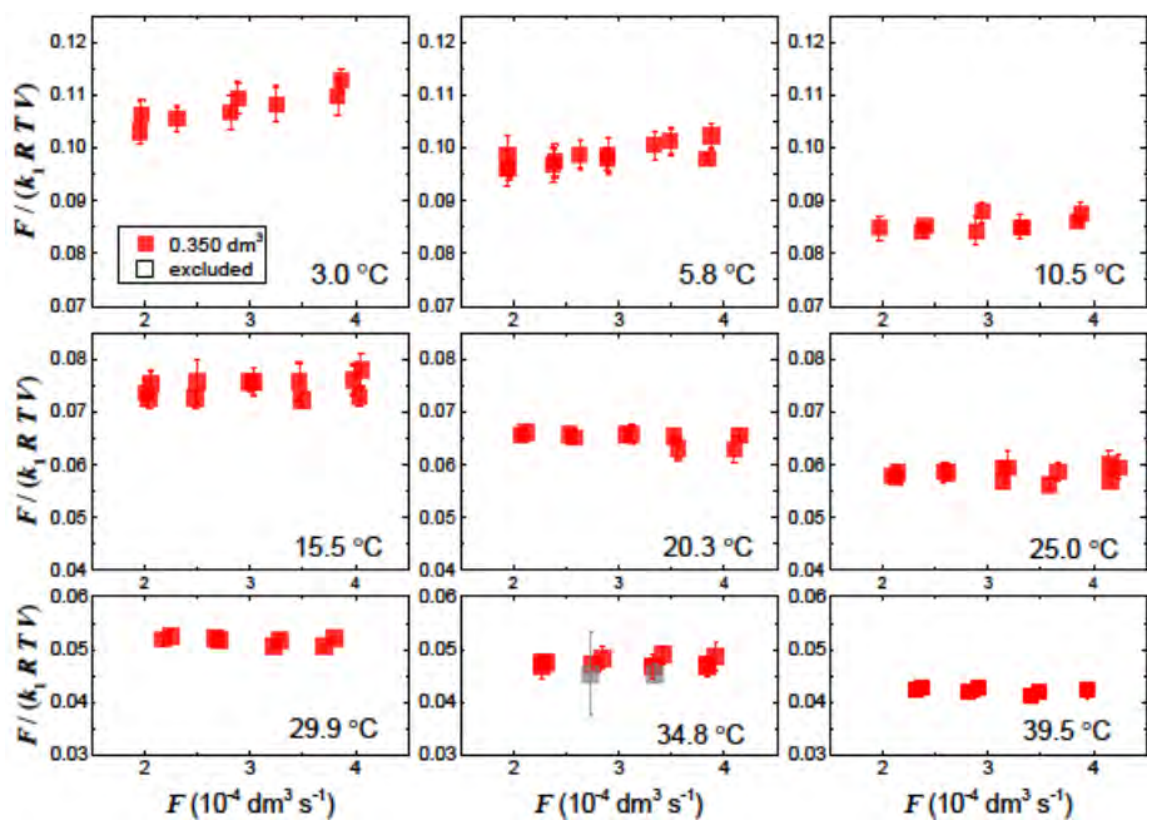

Figure S5. Plots of values of $F /\left(k_{1} R T V\right)$ against $F$ at each temperature for $0.35 \mathrm{dm}^{3}$ of a-seawater at $4.452 \%$. Error bars represent $2 \sigma$ due to errors of values of $k_{1}$ as described in Sect. S2. Grey symbols represent the data excluded for calculating the average.

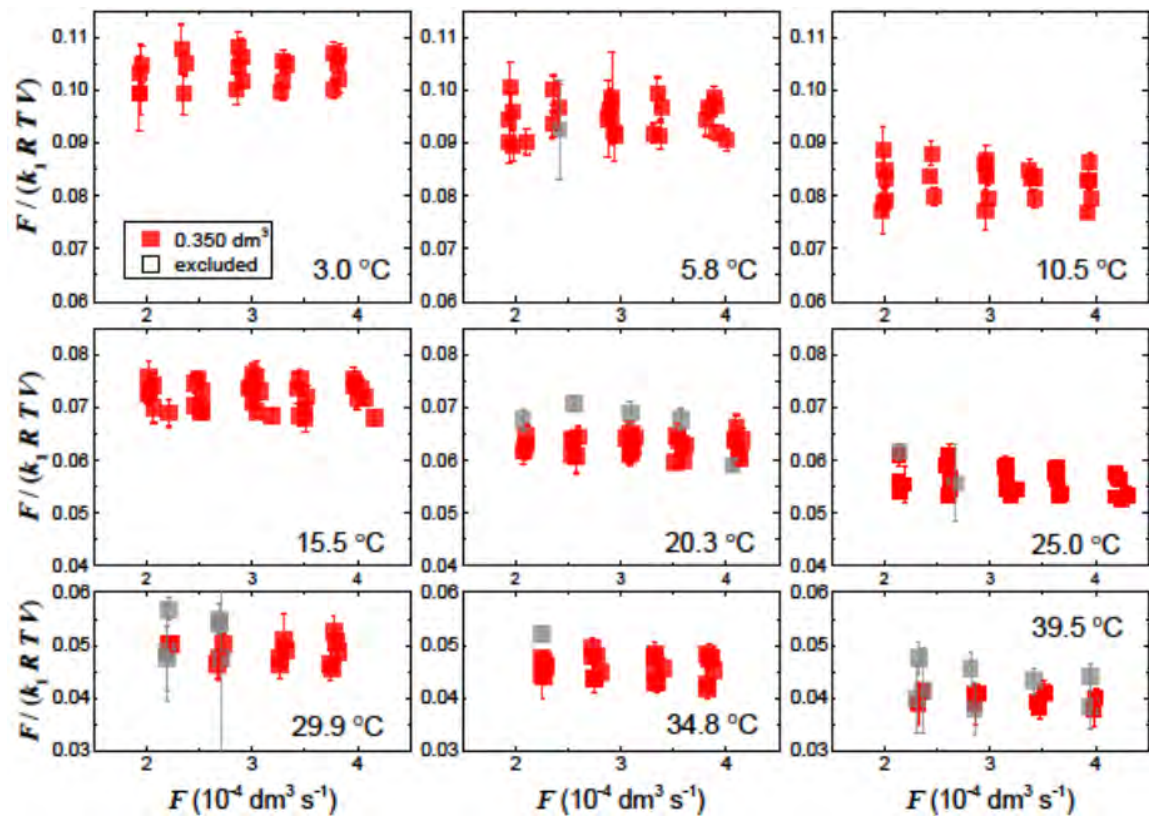

Figure S6. Plots of values of $F /\left(k_{1} R T V\right)$ against $F$ at each temperature for $0.35 \mathrm{dm}^{3}$ of a-seawater at $8.921 \%$. Error bars represent $2 \sigma$ due to errors of values of $k_{1}$ as described in Sect. S2. Grey symbols represent the data excluded for calculating the average. 


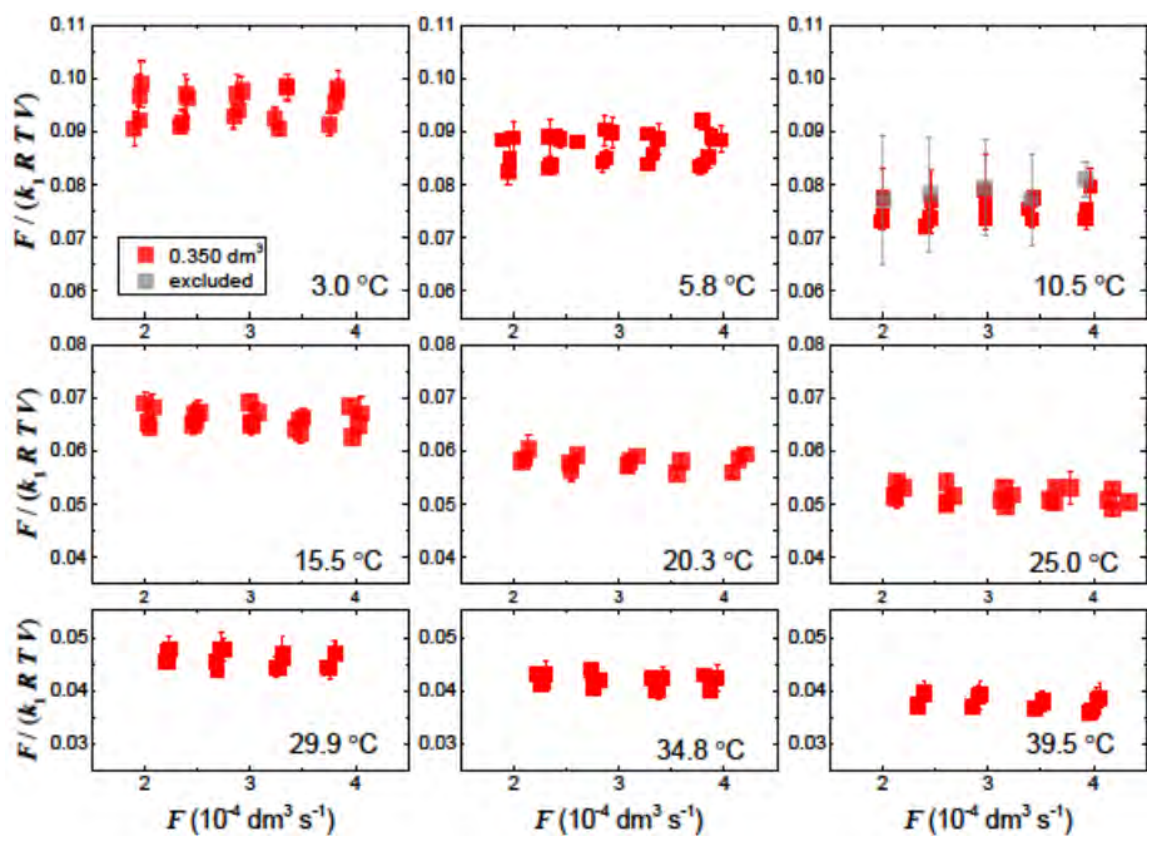

Figure S7. Plots of values of $F /\left(k_{1} R T V\right)$ against $F$ at each temperature for $0.35 \mathrm{dm}^{3}$ of a-seawater at $21.520 \%$. Error bars represent

$2 \sigma$ due to errors of values of $k_{1}$ as described in Sect. S2. Grey symbols represent the data excluded for calculating the average.

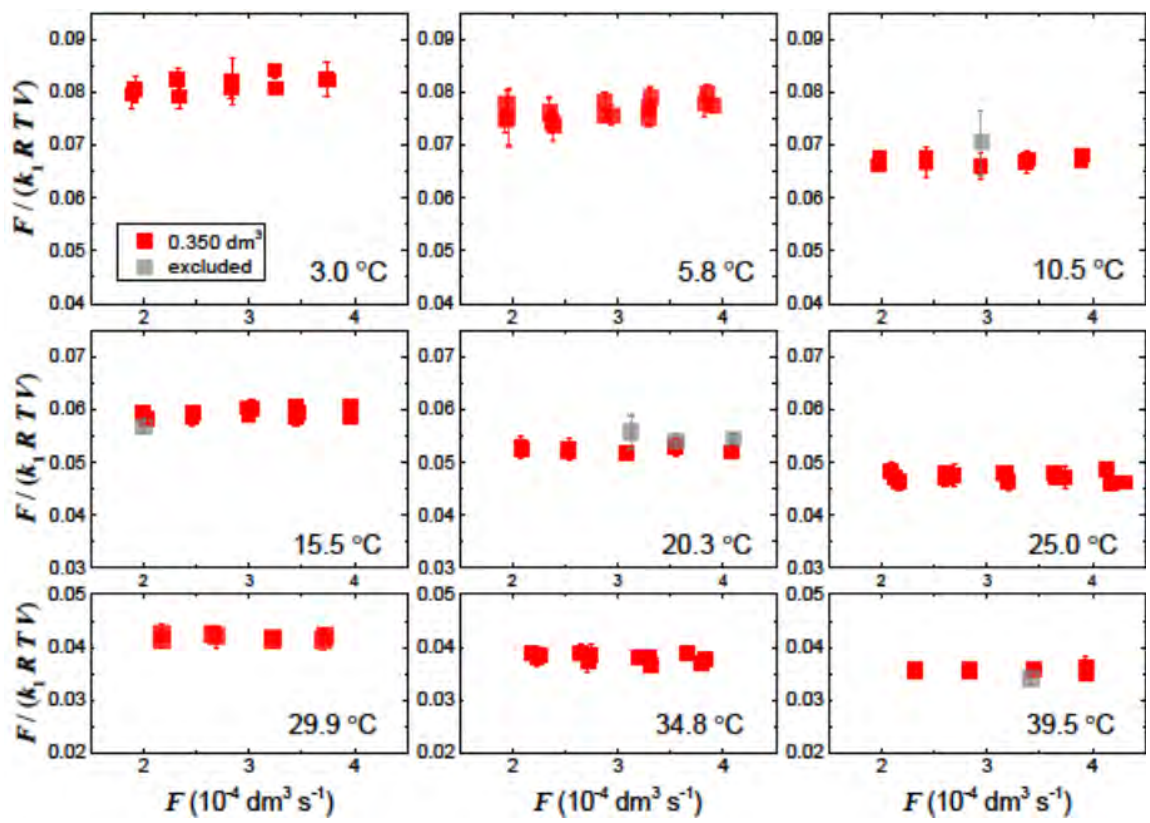

Figure S8. Plots of values of $F /\left(k_{1} R T V\right)$ against $F$ at each temperature for $0.35 \mathrm{dm}^{3}$ of a-seawater at 51.534\%o. Error bars represent $2 \sigma$ due to errors of values of $k_{1}$ as described in Sect. S2. Grey symbols represent the data excluded for calculating the average. 

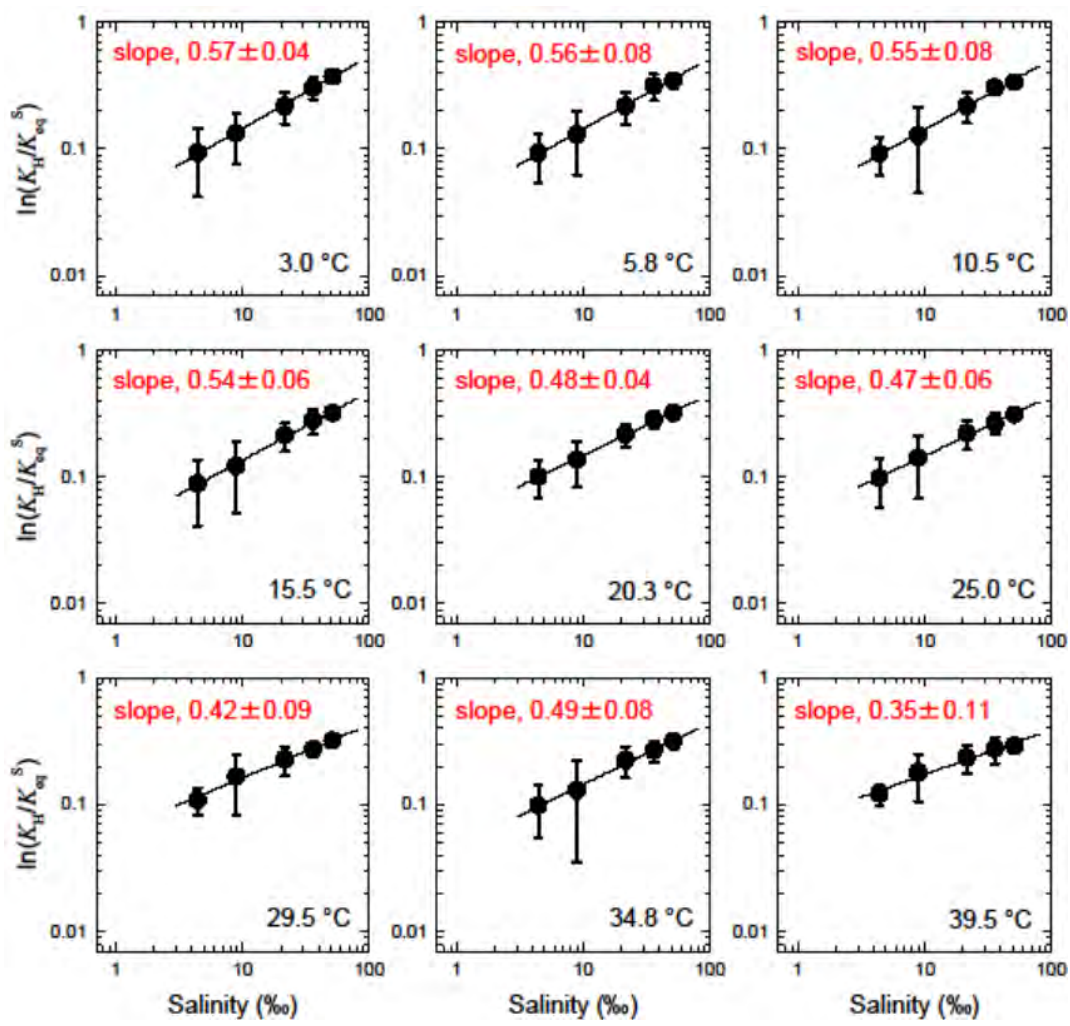

Figure S9. $\log -\log$ plots for $\ln \left(K_{\mathrm{H}}(T) / K_{\mathrm{eq}}{ }^{S}(T)\right)$ vs. salinity in a-seawater at each temperature. Bold lines represent the fitting obtained by a liner regression. Errors are those at $95 \%$ confidence level for the regression only.

5 Table S2. Values of $k_{s}$ (Eq. (17)) and comparison of values of $K_{\text {eq }}{ }^{s}$ calculated at each temperature by Eq. (17) with those by Eq. (22).

\begin{tabular}{|c|c|c|c|c|c|c|}
\hline \multirow{2}{*}{$\begin{array}{c}\text { Temperature } \\
\left({ }^{\circ} \mathrm{C}\right)\end{array}$} & \multirow{2}{*}{$\begin{array}{c}k_{\mathrm{s}} \\
\left(\%{ }^{-1}\right)\end{array}$} & \multicolumn{3}{|c|}{$\left[K_{\mathrm{eq}}{ }^{\mathrm{S}}\right.$ from Eq. $\left.(17)\right] /\left[K_{\mathrm{eq}}{ }^{\mathrm{S}}\right.$ from Eq. $\left.(22)\right]$} & \multicolumn{2}{|c|}{$\left[K_{\mathrm{eq}}^{\mathrm{S}}\right.$ at $\left.30 \% 0\right] /\left[K_{\mathrm{eq}}^{\mathrm{S}}\right.$ at $\left.40 \% 0\right]$} \\
\hline & & at $30 \%$ & at $35 \%$ & at $40 \%$ & Eq. (17) & Eq. (22) \\
\hline 3.0 & 0.00811 & 1.027 & 1.008 & 0.988 & 1.084 & 1.043 \\
\hline 5.8 & 0.00785 & 1.033 & 1.014 & 0.995 & 1.082 & 1.042 \\
\hline 10.5 & 0.00768 & 1.033 & 1.016 & 0.997 & 1.080 & 1.042 \\
\hline 15.5 & 0.00718 & 1.044 & 1.028 & 1.012 & 1.074 & 1.041 \\
\hline 20.3 & 0.00728 & 1.037 & 1.020 & 1.003 & 1.076 & 1.040 \\
\hline 25.0 & 0.00704 & 1.040 & 1.024 & 1.008 & 1.073 & 1.039 \\
\hline 29.9 & 0.00731 & 1.027 & 1.010 & 0.992 & 1.076 & 1.039 \\
\hline 34.8 & 0.00713 & 1.029 & 1.012 & 0.995 & 1.074 & 1.038 \\
\hline 39.5 & 0.00709 & 1.026 & 1.010 & 0.992 & 1.073 & 1.038 \\
\hline
\end{tabular}




\section{S5. Discussion of potential reason for this salting-out effect of $\mathrm{CH}_{2} \mathrm{~F}_{2}$ solubility in a-seawater (deviation from}

\section{Sechenov relationship)}

The reason that the salting-out effect of $\mathrm{CH}_{2} \mathrm{~F}_{2}$ solubility in a-seawater depends on $S^{0.5}$ is not clear. Specific properties of $\mathrm{CH}_{2} \mathrm{~F}_{2}$-small molecular volume, which results in small work of cavity creation (Graziano, 2004; 2008), and large solute-

5 solvent attractive potential energy in water and a-seawater- may cause deviation from Sechenov relationship. This possibility may be discussed here.

I calculate Ben-Naim standard Gibbs energy $\Delta G^{*}$, enthalpy $\Delta H^{*}$, and entropy $\Delta S^{\circ}$ changes for dissolution of $\mathrm{CH}_{2} \mathrm{~F}_{2}$ in water because these values correspond to the values for the transfer from a fixed position in the gas phase to a fixed position in water. Values of $\Delta G^{*}, \Delta H^{*}$, and $\Delta S^{\circ}$ are calculated on the basis of the Ostwald solubility coefficient, $L(T)$, as follows.

10

$$
\begin{aligned}
& \ln (L(T))=\ln \left(R T K_{\mathrm{eq}}{ }^{S}(T)\right) \\
& \Delta G^{*}=R^{\prime} T \ln (L(T)) \\
& \Delta H^{*}=-\frac{\partial}{\partial(1 / T)}\left(\frac{\Delta G^{\cdot}}{T}\right) \\
& \Delta S^{*}=\frac{\Delta H^{-}-\Delta G^{\circ}}{T}
\end{aligned}
$$

where both $R$ and $R^{\prime}$ represent gas constant but their units are different: $R=0.0821$ in atm $\mathrm{dm}^{3} \mathrm{~K}^{-1} \mathrm{~mol}^{-1} ; R^{\prime}=8.314$ in $\mathrm{J} \mathrm{K}^{-1}$ $15 \mathrm{~mol}^{-1}$.

Combining Eqs. (B1), (B2), (B3), and (B4) with Eqs. (14) and (15), $\Delta G^{*}\left(\mathrm{~kJ} \mathrm{~mol}^{-1}\right), \Delta H^{*}\left(\mathrm{~kJ} \mathrm{~mol}^{-1}\right)$, and $\Delta S^{*}\left(\mathrm{~J} \mathrm{~mol}^{-1}\right.$ $\mathrm{K}^{-1}$ ) are represented by $\Delta G_{\text {sol }}$ and $\Delta H_{\text {sol }}$ as follows:

$$
\begin{aligned}
\Delta G^{*} & =\Delta G_{\text {sol }}+R^{\prime} T \ln (R T) \\
\Delta H^{*} & =\Delta H_{\text {sol }}+R^{\prime} T
\end{aligned}
$$

$$
\Delta S^{\prime}=\frac{\Delta H_{\text {sol }}-\Delta G_{\text {sol }}}{T}+R^{\prime}-R^{\prime} \ln (R T)
$$

Values of $\Delta G^{\circ}, \Delta H^{\circ}$, and $\Delta S^{\circ}$ calculated at $298 \mathrm{~K}$ are listed in Table S3. Table S3 also lists values of $\Delta G^{\circ}, \Delta H^{\circ}$, and $\Delta S^{\circ}$ reported for $\mathrm{CH}_{3} \mathrm{~F}$ and $\mathrm{C}_{2} \mathrm{H}_{6}$ (Graziano, 2004) and $\mathrm{CH}_{4}$ (Graziano, 2008) at $298 \mathrm{~K}$. The chemicals, which having a methyl group, in Table $\mathrm{S} 3$ are classified into two groups $\left(\mathrm{CH}_{2} \mathrm{~F}_{2}\right.$ and $\mathrm{CH}_{3} \mathrm{~F} ; \mathrm{CH}_{4}$ and $\left.\mathrm{C}_{2} \mathrm{H}_{6}\right)$ according to $\Delta G$.

Table S3 lists values of $\Delta G_{\mathrm{c}}, E_{a}$ and $\Delta H^{h}$ deduced using a scaled particle theory (Granziano, 2004; 2008). $\Delta G_{c}$ is the

25 work of cavity creation to insert a solute in a solvent. $E_{a}$ is a solute-solvent attractive potential energy and accounts for the solute-solvent interactions consisting of dispersion, dipole-induced dipole, and dipole-dipole contributions. $\Delta H^{h}$ is enthalpy of solvent molecules reorganization caused by solute insertion. The solvent reorganization mainly involves a rearrangement of H-bonds.

$\Delta G_{\mathrm{c}}$ is entropic in nature in all liquids, being a measure of the excluded volume effect due to a reduction in the spatial 30 configurations accessible to liquid molecules upon cavity creation. Hence, $\mathrm{C}_{2} \mathrm{H}_{6}$ has larger value of $\Delta G_{\mathrm{c}}$ than $\mathrm{CH}_{3} \mathrm{~F}$ and $\mathrm{CH}_{4}$. $\Delta G_{\mathrm{c}}, E_{a}$, and $\Delta H^{h}$ are related to $\Delta G^{\circ}$ and $\Delta H^{*}$ as follows (Graziano, 2008): 


$$
\begin{aligned}
& \Delta G^{\cdot}=\Delta G_{\mathrm{c}}+E_{a} \\
& \Delta H^{\cdot}=E_{a}+\Delta H^{h}
\end{aligned}
$$

Table S3 thus suggests that smaller value of $\Delta G^{*}$ of $\mathrm{CH}_{3} \mathrm{~F}$ than $\mathrm{CH}_{4}$ is due to large solute-solvent attractive potential energy $\left(-E_{a}\right)$ of $\mathrm{CH}_{3} \mathrm{~F}$.

Table S3. Ben-Naim standard hydration Gibbs energy $\Delta G^{\circ}$, enthalpy $\Delta H^{*}$, and entropy $\Delta S^{*}$ changes for dissolution of $\mathrm{CH}_{2} \mathrm{~F}_{2}$ at 298 $\mathrm{K}$ determined here and the corresponding values and values of $\Delta G_{c}, E_{a}$ and $\Delta H^{h}$ reported for $\mathrm{CH}_{3} \mathrm{~F}$ and $\mathrm{C}_{2} \mathrm{H}_{6}(\mathrm{Granziano}, 2004)$ and $\mathrm{CH}_{4}$ (Graziano, 2008).

\begin{tabular}{ccccccc}
\hline & $\begin{array}{c}\Delta G \\
\left(\mathrm{~kJ} \mathrm{~mol}^{-1}\right)\end{array}$ & $\begin{array}{c}\Delta H^{-} \\
\left(\mathrm{kJ} \mathrm{mol}^{-1}\right)\end{array}$ & $\begin{array}{c}\Delta S^{*} \\
\left(\mathrm{~J} \mathrm{~K}^{-1} \mathrm{~mol}^{-1}\right)\end{array}$ & $\begin{array}{c}\Delta G_{\mathrm{c}} \\
\left(\mathrm{kJ} \mathrm{mol}^{-1}\right)\end{array}$ & $\begin{array}{c}E_{a} \\
\left(\mathrm{~kJ} \mathrm{~mol}^{-1}\right)\end{array}$ & $\begin{array}{c}\Delta H^{h} \\
\left(\mathrm{~kJ} \mathrm{~mol}^{-1}\right)\end{array}$ \\
\hline $\mathrm{CH}_{2} \mathrm{~F}_{2}$ & -1.1 & -14.7 & -45.4 & & & \\
$\mathrm{CH}_{3} \mathrm{~F}$ & -0.9 & -15.8 & -50.0 & 23.3 & -24.3 & 8.5 \\
$\mathrm{CH}_{4}$ & 8.4 & -10.9 & -64.7 & 22.9 & -14.5 & 3.7 \\
$\mathrm{C}_{2} \mathrm{H}_{6}$ & 7.7 & -17.5 & -84.5 & 28.4 & -20.7 & 3.2 \\
\hline
\end{tabular}

Graziano (2008) definitively explained the salting-out of $\mathrm{CH}_{4}$ by sodium chloride at molecular level on the basis of a scaled particle theory. He explained that $\Delta G_{\mathrm{c}}$ increase was linearly related to the increase in the volume packing density of the solutions $\left(\xi_{3}\right)$ with adding $\mathrm{NaCl}$. Such an increase of $\Delta G_{\mathrm{c}}$ is probably the case for salting-out of $\mathrm{CH}_{2} \mathrm{~F}_{2}$ by a-seawater observed in this study. He also explained that $E_{a}$ was linearly related to the increase in $\xi_{3}$ assuming that a fraction of the dipole-induced dipole attractions could be taken into account by the parameterization of the dispersion contribution.

I think the possibility that $E_{\mathrm{a}}$ may be nonlinearly related to the increase in $\xi_{3}$ because of dipole-dipole interaction between $\mathrm{CH}_{2} \mathrm{~F}_{2}$ and solvents. Temperature dependence in Eq. (22) suggests that salting-out effect of $\mathrm{CH}_{2} \mathrm{~F}_{2}$ by a-seawater is enthalpic. Eqs. (22) and (B9) thus suggests that the salting-out of $\mathrm{CH}_{2} \mathrm{~F}_{2}$ is mostly related to change in $E_{a}$. $\mathrm{CH}_{2} \mathrm{~F}_{2}$ has relatively small value of $\Delta G_{\mathrm{c}}$ because of its small molecular volume compared to other chemicals such as $\mathrm{C}_{2} \mathrm{H}_{6}$. Accordingly, $\Delta G^{*}$, that is, solubility of $\mathrm{CH}_{2} \mathrm{~F}_{2}$ would depend on $E_{a}$ rather than $\Delta G_{\mathrm{c}}$. Therefore, I think that specific properties of $\mathrm{CH}_{2} \mathrm{~F}_{2}-$

20 small molecular volume, which results in small work of cavity creation (Graziano, 2004; 2008), and large solute-solvent attractive potential energy in water and a-seawater- may cause deviation from Sechenov relationship.

\section{References}

Graziano, G.: Case study of enthalpy-entropy noncompensation. Journal of Chemical Physics, 120, 4467-4471, doi: $2510.1063 / 1.1644094,2004$.

Graziano, G.: Salting out of methane by sodium chloride: A scaled particle theory study. Journal of Chemical Physics, 129, 084506, doi: 10.1063/1.2972979, 2008. 
S6. Estimated results (Sect. 3.3) for monthly amount of $\mathrm{CH}_{2} \mathrm{~F}_{2}$ dissolved in the ocean mixed layer at solubility equilibrium with the atmospheric $\mathrm{CH}_{2} \mathrm{~F}_{2}\left(1\right.$ patm) and the depth distribution of the $\mathrm{CH}_{2} \mathrm{~F}_{2}$ dissolved in each semihemisphere

Table S4. Monthly amount of $\mathrm{CH}_{2} \mathrm{~F}_{2}$ dissolved in the ocean mixed layer at solubility equilibrium with the atmospheric $\mathrm{CH}_{2} \mathrm{~F}_{2}$ (partial pressure, 1 patm) and the depth distribution of the $\mathrm{CH}_{2} \mathrm{~F}_{2}$ dissolved in the southern semi-hemisphere $\left(90^{\circ} \mathrm{S}-30^{\circ} \mathrm{S}\right)$.

\begin{tabular}{cccccccc}
\hline & \multirow{2}{*}{$\begin{array}{c}\text { Amount } \\
\left(\mathrm{Gg} \mathrm{patm}^{-1}\right)\end{array}$} & \multicolumn{5}{c}{$\begin{array}{c}\text { Distribution of the amount of } \mathrm{CH}_{2} \mathrm{~F}_{2} \text { dissolved in the ocean mixed layer } \\
\text { with respect to the ocean mixed layer depth (\%) }\end{array}$} \\
\cline { 3 - 7 } & & $10-100 \mathrm{~m}$ & $100-200 \mathrm{~m}$ & $200-300 \mathrm{~m}$ & $300-400 \mathrm{~m}$ & $400-500 \mathrm{~m}$ & $500-600 \mathrm{~m}$ \\
\hline January & 0.0169 & 94.9 & 2.9 & 1.0 & 0.5 & 0.3 & 0.3 \\
February & 0.0201 & 92.1 & 3.6 & 2.9 & 1.0 & 0.3 & 0.0 \\
March & 0.0255 & 87.8 & 9.2 & 1.7 & 0.7 & 0.2 & 0.4 \\
April & 0.0338 & 66.5 & 31.8 & 1.1 & 0.2 & 0.1 & 0.2 \\
May & 0.0409 & 48.5 & 48.1 & 2.2 & 0.8 & 0.3 & 0.0 \\
June & 0.0510 & 26.8 & 62.7 & 8.0 & 1.7 & 0.8 & 0.1 \\
July & 0.0571 & 14.1 & 69.3 & 12.2 & 3.3 & 0.9 & 0.1 \\
August & 0.0640 & 8.5 & 65.8 & 17.0 & 6.2 & 2.3 & 0.2 \\
September & 0.0609 & 13.5 & 61.0 & 14.6 & 8.2 & 2.7 & 0.0 \\
October & 0.0504 & 24.7 & 58.6 & 12.1 & 2.9 & 1.4 & 0.3 \\
November & 0.0335 & 60.4 & 30.5 & 4.6 & 2.2 & 2.3 & 0.1 \\
December & 0.0196 & 95.1 & 4.3 & 0.4 & 0.2 & 0.0 & 0.0 \\
\hline
\end{tabular}

Table S5. Monthly amount of $\mathrm{CH}_{2} \mathrm{~F}_{2}$ dissolved in the ocean mixed layer at solubility equilibrium with the atmospheric $\mathrm{CH}_{2} \mathrm{~F}_{2}$ (partial pressure, 1 patm) and the depth distribution of the $\mathrm{CH}_{2} \mathrm{~F}_{2}$ dissolved in the southern semi-hemisphere $\left(30^{\circ} \mathrm{S}-0^{\circ} \mathrm{S}\right)$.

\begin{tabular}{cccccccc}
\hline & \multirow{2}{*}{$\begin{array}{c}\text { Amount } \\
\left(\mathrm{Gg} \mathrm{patm}^{-1}\right)\end{array}$} & \multicolumn{5}{c}{$\begin{array}{c}\text { Distribution of the amount of } \mathrm{CH}_{2} \mathrm{~F}_{2} \text { dissolved in the ocean mixed layer } \\
\text { with respect to the ocean mixed layer depth (\%) }\end{array}$} \\
\cline { 3 - 7 } & 0.0084 & 99.6 & 0.4 & 0 & 0 & 0 & 0 \\
\hline January & $0.100 \mathrm{~m}$ & $100-200 \mathrm{~m}$ & $200-300 \mathrm{~m}$ & $300-400 \mathrm{~m}$ & $400-500 \mathrm{~m}$ & $500-600 \mathrm{~m}$ \\
February & 0.0084 & 99.7 & 0.3 & 0 & 0 & 0 & 0 \\
March & 0.0089 & 100.0 & 0 & 0 & 0 & 0 & 0 \\
April & 0.0106 & 100.0 & 0 & 0 & 0 & 0 & 0 \\
May & 0.0131 & 100.0 & 0 & 0 & 0 & 0 & 0 \\
June & 0.0163 & 97.1 & 2.9 & 0 & 0 & 0 & 0 \\
July & 0.0189 & 80.1 & 19.9 & 0 & 0 & 0 & 0 \\
August & 0.0193 & 73.1 & 26.9 & 0 & 0 & 0 & 0 \\
September & 0.0165 & 82.2 & 17.8 & 0 & 0 & 0 & 0 \\
October & 0.0124 & 94.6 & 5.4 & 0 & 0 & 0 & 0 \\
November & 0.0097 & 99.9 & 0.1 & 0 & 0 & 0 & 0 \\
December & 0.0087 & 100.0 & 0 & 0 & 0 & 0 & 0 \\
\hline
\end{tabular}


Table S6. Monthly amount of $\mathrm{CH}_{2} \mathrm{~F}_{2}$ dissolved in the ocean mixed layer at solubility equilibrium with the atmospheric $\mathrm{CH}_{2} \mathrm{~F}_{2}$ (partial pressure, 1 patm) and the depth distribution of the $\mathrm{CH}_{2} \mathrm{~F}_{2}$ dissolved in the northern semi-hemisphere $\left(0^{\circ} \mathrm{N}-30^{\circ} \mathrm{N}\right)$.

\begin{tabular}{cccccccc}
\hline & $\begin{array}{c}\text { Amount } \\
\left(\mathrm{Gg} \mathrm{patm}^{-1}\right)\end{array}$ & \multicolumn{5}{c}{$\begin{array}{c}\text { Distribution of the amount of } \mathrm{CH}_{2} \mathrm{~F}_{2} \text { dissolved in the ocean mixed layer } \\
\text { with respect to the ocean mixed layer depth (\%) }\end{array}$} \\
\cline { 3 - 7 } & & $10-100 \mathrm{~m}$ & $100-200 \mathrm{~m}$ & $200-300 \mathrm{~m}$ & $300-400 \mathrm{~m}$ & $400-500 \mathrm{~m}$ & $500-600 \mathrm{~m}$ \\
\hline January & 0.0132 & 96.4 & 3.6 & 0 & 0 & 0 & 0 \\
February & 0.0126 & 95.9 & 4.1 & 0 & 0 & 0 & 0 \\
March & 0.0107 & 98.7 & 1.3 & 0 & 0 & 0 & 0 \\
April & 0.0087 & 99.8 & 0.2 & 0 & 0 & 0 & 0 \\
May & 0.0079 & 100.0 & 0 & 0 & 0 & 0 & 0 \\
June & 0.0080 & 100.0 & 0 & 0 & 0 & 0 & 0 \\
July & 0.0084 & 100.0 & 0 & 0 & 0 & 0 & 0 \\
August & 0.0082 & 100.0 & 0 & 0 & 0 & 0 & 0 \\
September & 0.0080 & 100.0 & 0 & 0 & 0 & 0 & 0 \\
October & 0.0086 & 100.0 & 0 & 0 & 0 & 0 & 0 \\
November & 0.0100 & 100.0 & 0 & 0 & 0 & 0 & 0 \\
December & 0.0118 & 100.0 & 0 & 0 & 0 & 0 \\
\hline
\end{tabular}

5 Table S7. Monthly amount of $\mathrm{CH}_{2} \mathrm{~F}_{2}$ dissolved in the ocean mixed layer at solubility equilibrium with the atmospheric $\mathrm{CH}_{2} \mathrm{~F}_{2}$ (partial pressure, 1 patm) and the depth distribution of the $\mathrm{CH}_{2} \mathrm{~F}_{2}$ dissolved in the northern semi-hemisphere $\left(30^{\circ} \mathrm{N}-90^{\circ} \mathrm{N}\right)$.

\begin{tabular}{|c|c|c|c|c|c|c|c|}
\hline & \multirow{2}{*}{$\begin{array}{c}\text { Amount } \\
\left(\mathrm{Gg}^{-1} \text { patm }^{-1}\right)\end{array}$} & \multicolumn{6}{|c|}{$\begin{array}{c}\text { Distribution of the amount of } \mathrm{CH}_{2} \mathrm{~F}_{2} \text { dissolved in the ocean mixed layer } \\
\text { with respect to the ocean mixed layer depth (\%) }\end{array}$} \\
\hline & & $10-100 \mathrm{~m}$ & $100-200 \mathrm{~m}$ & $200-300 \mathrm{~m}$ & $300-400 \mathrm{~m}$ & $400-500 \mathrm{~m}$ & $500-600 \mathrm{~m}$ \\
\hline January & 0.0205 & 41.3 & 50.1 & 7.0 & 1.4 & 0.2 & 0.0 \\
\hline February & 0.0225 & 34.5 & 55.3 & 7.1 & 2.3 & 0.6 & 0.2 \\
\hline March & 0.0208 & 49.7 & 42.3 & 4.9 & 1.7 & 0.7 & 0.6 \\
\hline April & 0.0147 & 79.7 & 17.6 & 1.7 & 0.4 & 0.0 & 0.6 \\
\hline May & 0.0081 & 90.1 & 9.9 & 0 & 0 & 0 & 0 \\
\hline June & 0.0055 & 97.7 & 2.3 & 0 & 0 & 0 & 0 \\
\hline July & 0.0045 & 96.6 & 3.4 & 0 & 0 & 0 & 0 \\
\hline August & 0.0048 & 94.4 & 5.6 & 0 & 0 & 0 & 0 \\
\hline September & 0.0059 & 97.7 & 2.3 & 0 & 0 & 0 & 0 \\
\hline October & 0.0084 & 99.6 & 0.4 & 0 & 0 & 0 & 0 \\
\hline November & 0.0121 & 89.6 & 10.4 & 0.1 & 0 & 0 & 0 \\
\hline December & 0.0163 & 71.0 & 26.1 & 2.9 & 0 & 0 & 0 \\
\hline
\end{tabular}

